\title{
Verandermanagement en beleid: Waarom vertonen professionals weerstand tegen nieuw beleid?
}

\author{
Geaccepteerd artikel voor 'Bestuurskunde' \\ Dr. L.G. (Lars) Tummers
}

Tummers, L.G. (2014). Verandermanagement en beleid: Waarom vertonen professionals weerstand tegen nieuw beleid? Bestuurskunde.

Dr. L.G. Tummers

Department of Public Administration, Erasmus University Rotterdam, the Netherlands \& Center for the Study of Law \& Society, University of California, Berkeley, The United States Tummers@fsw.eur.nl 


\section{Leader/abstract}

Professionals vertonen vaak weerstand tegen nieuw overheidsbeleid dat ze moeten uitvoeren. Dit kan de legitimiteit en effectiviteit van beleid aantasten. Het doel van dit artikel is om de belangrijkste oorzaken voor weerstand tegen nieuw overheidsbeleid te identificeren. Ik gebruik hiervoor het model van beleidsvervreemding, dat uit vijf dimensies bestaat: strategische, tactische en operationele machteloosheid, en zinloosheid voor de samenleving en voor de eigen cliënten. De resultaten laten zien dat wanneer professionals het beleid als zinloos ervaren, zij veel weerstand vertonen. Weinig ervaren invloed is veel minder belangrijk. Een belangrijke aanbeveling is dus om meer aandacht te geven aan de zinvolheid van beleid. Denken professionals dat het beleid iets toevoegt voor de samenleving of voor hun cliënten? Tot slot laten de resultaten zien dat de impact van beleidsvervreemding 'contingent' is: de effecten zijn deels afhankelijk van de professie waartoe iemand behoort. Het artikel eindigt met tips voor beleidsmakers, managers en professionals.

Engelstalige titel: Change management and public policy: Why do public professionals resist new policies?

\section{Abstract in English}

Professionals often have problems with governmental policies they have to implement. This can lead to diminished legitimacy and lower policy performance. The goal of this article is to identify the main reasons why professionals resist implementing new policies. An interdisciplinary approach is taken. From public administration literature, I use the policy alienation model, which consists of five dimensions: strategic, tactical and operational powerlessness, societal meaninglessness and client meaninglessness. These are possible reasons why professionals resist public policies ("resistance to change", a concept drawn from change management literature). We test these assumptions using a survey among 1,317 healthcare professionals. The results show that when professionals experience that a policy is meaningless for society or for their own clients, they show strong resistance. A lack of perceived influence is much less important in explaining resistance, although this is partly dependent on the profession someone belong to. The policy alienation model can help policy makers and managers to develop policies which are accepted by professionals. The article ends with practical recommendations for policy makers, managers and professionals.

Key words: Public policy, change management, policy implementation, public management, resistance to change 


\section{Introductie}

In de bestuurskunde is een hevig debat gaande over de rol van professionals in de publieke dienstverlening (Brandsen \& Honingh, 2013; De Bruijn, 2010; Noordegraaf, 2011; Tonkens et al., 2013; Van den Brink et al., 2006). Onderzoekers schrijven over 'moeilijke tijden voor professionals' (Gleeson \& Knights, 2006) 'aanvallen' op professionals (Ackroyd, 1996) en professionals die 'onder druk staan' (Noordegraaf \& Steijn, 2013). Een belangrijke oorzaak voor de problemen die professionals ervaren is de invloed van prestatiemanagement en een (vermeende) toegenomen macht van managers (Klopper-Kes et al., 2010; Raelin, 1986). Maar er is meer. Noordegraaf (2014) geeft in een recent artikel een overzicht van verschillende uitdagingen voor hedendaagse professionals, zoals hogere eisen van cliënten, minder baanzekerheid, schandalen uitgemeten in de media, en gefragmenteerde carrièrepaden.

In dit artikel richt ik me op de problemen die professionals hebben met nieuw overheidsbeleid. Het doel van dit artikel is om de belangrijkste oorzaken voor weerstand tegen nieuw beleid te identificeren. Er zijn verschillende voorbeelden te vinden waar professionals weerstand vertoonden tegen de introductie van beleid (Duyvendak et al., 2006; Noordegraaf \& Steijn, 2013). Zo hadden leraren uit Israël grote problemen met nieuw beleid dat erop gericht was de schooldagen te verlengen. Zij demonstreerden 64 dagen lang (!), wat ervoor zorgde dat tijdens deze periode 550.000 leerlingen geen onderwijs genoten (Berkovich, 2011). Wanneer professionals weerstand vertonen, kan dit de legitimiteit en effectiviteit van beleid in gevaar brengen (Ewalt \& Jennings, 2004). Professionals kunnen zich bijvoorbeeld minder inspannen, of zelfs het nieuwe beleid saboteren (Brehm \& Gates, 1999). Hiernaast kan het werkplezier van de professionals afnemen, wat kan leiden tot burnouts of zelfs stoppen met het werk (Nutting et al., 2011).

Verandermanagementliteratuur heeft een lange traditie in het onderzoeken van weerstand tegen veranderingen, zoals nieuw beleid (Carnall, 2007). Dit artikel maakt daarom gebruik van een interdisciplinaire aanpak, waar inzichten uit de bestuurskunde en de verandermanagement worden gecombineerd. Het doel is om de oorzaken voor weerstand tegen nieuw overheidsbeleid te bepalen. Om weerstand (hier: weerstand tegen nieuw beleid) te meten maak ik gebruik van het concept weerstand tegen veranderingen (Ford et al., 2008). De mogelijke oorzaken van weerstand worden gezocht in de vijf dimensies van het model van "beleidsvervreemding" ("policy alienation") (Tummers et al., 2009). Deze vijf dimensies zijn: strategische machteloosheid, tactische machteloosheid, operationele machteloosheid, zinloosheid voor de samenleving en zinloosheid voor de cliënten.

De belangrijkste toevoeging van dit artikel is aan verandermanagementliteratuur in de publieke sector. Kickert (2010) stelt dat er tot nu toe vrijwel geen aandacht specifiek publieke 
veranderingen zoals het invoeren van nieuw beleid. Hiernaast geven Kuipers e.a. (2014:3) aan dat het bestuurskundig perspectief vaak ontbreekt: "There still appears to be a gap in the literature on change management specifically regarding the public administration perspective". In dit artikel kijk ik daarom specifiek naar de weerstand van publieke professionals die nieuw overheidsbeleid moeten uitvoeren, en maak ik gebruik van een bestuurskundig model (dat van beleidsvervreemding) dat past bij deze context.

Ten tweede bouwt dit artikel voort op een eerder artikel over de invloed van beleidsvervreemding op weerstand tegen nieuw beleid (Tummers, 2011). Het 2011 artikel gebruikte een dataset van 478 zorgprofessionals uit 2009. Dit artikel gebruikt een nieuwe dataset van 1.317 zorgprofessionals, uitgevoerd in 2010. Door het onderzoek te repliceren met een nieuwe dataset kunnen we analyseren of de resultaten uit 2009 robuust zijn: in hoeverre is beleidsvervreemding echt van invloed op weerstand tegen nieuw beleid? Dit artikel voegt ook een nieuw element toe door te analyseren of de invloed van bepaalde dimensies van beleidsvervreemding op weerstand sterker is voor sommige professies. Met andere woorden: Welke dimensies van beleidsvervreemding zijn belangrijk voor welk type professional? Is het bijvoorbeeld vooral voor medische professionals belangrijk om hen te betrekken bij de uitvoering? Hebben niet-medische professionals minder moeite met opgelegd beleid? Dit bouwt voort op institutionele theorieën, die stellen dat de professie waartoe iemand behoort invloed heeft op zijn of haar houding en gedrag (Freidson, 2001; Powell \& Colyvas, 2008; Scott, 1994). Ik laat zien dat het model van beleidsvervreemding deels 'contingent' is: de impact van verschillende dimensies van beleidsvervreemding hangt af van de professie waartoe iemand behoort. Deze resultaten laten zien dat het belangrijk is om te analyseren welke professie een bepaald beleid moet uitvoeren.

De volgende secties beschrijven achtereenvolgens het theoretisch raamwerk, de methoden en de resultaten. Het artikel sluit af met een conclusie en discussie, waarbij ik specifiek inga op praktische tips voor beleidsmakers, managers en professionals.

\section{Theoretisch raamwerk}

\section{Het model van beleidsvervreemding}

Het model van beleidsvervreemding komt voort uit werkvervreemdingsliteratuur in de arbeids- en organisatiesociologie. Karl Marx (1961 [1844]) kan gezien worden als een van de belangrijke grondleggers van de werkvervreemdingsliteratuur. Veel sociale wetenschappers hebben voortgebouwd op het werk van Marx. Hierdoor zijn er verschillende betekenissen aan het begrip werkvervreemding gegeven. Seeman (1959) heeft deze betekenissen onderscheiden in vijf dimensies van werkvervreemding: machteloosheid, zinloosheid, 
normloosheid, sociale isolatie en zelfvervreemding. De classificatie van Seeman is ook gebruikt om de dimensies van beleidsvervreemding te bepalen. Beleidsvervreemding bestaat uit twee hoofddimensies: machteloosheid en zinloosheid (voor een uitgebreide bespreking, zie Tummers, 2011). Binnen de vervreemdingsliteratuur worden de dimensies machteloosheid en zinloosheid als zeer belangrijk gezien (Kanungo, 1982). Zo stellen DeHart-Davis en Pandey (2005:133) dat machteloosheid en zinloosheid "the key psychological ingredients of alienation" zijn.

Bij beleidsvervreemding gaat machteloosheid over de mate van invloed die publieke professionals ervaren op het beleidsprogramma dat ze uitvoeren. Professionals kunnen zich bijvoorbeeld machteloos voelen als zij het gevoel hebben dat ze geen invloed hebben op de ontwikkeling van het beleid in hun eigen organisatie. Zinloosheid verwijst naar de perceptie van professionals over de toegevoegde waarde van het beleid voor de samenleving of hun eigen cliënten. Om de (hoofd)dimensies machteloosheid en zinloosheid specifieker te maken is een onderscheid gemaakt tussen strategische, tactische en operationele machteloosheid, en tussen zinloosheid voor de maatschappij en voor de cliënten. Dit is weergegeven in Tabel 1.

Tabel 1 Vijf dimensies van beleidsvervreemding

\begin{tabular}{|cc|}
\hline Dimensie & Definitie \\
\hline Strategische machteloosheid & $\begin{array}{r}\text { De mate van gepercipieerde invloed van professionals op de inhoud } \\
\text { van het beleid, zoals vastgesteld in wet- en regelgeving. }\end{array}$ \\
\hline Tactische machteloosheid & $\begin{array}{r}\text { De mate van gepercipieerde invloed van professionals op de manier } \\
\text { waarop hun organisatie het beleid implementeert. }\end{array}$ \\
\hline Operationele machteloosheid & $\begin{array}{r}\text { De mate van gepercipieerde invloed van professionals op de manier } \\
\text { waarop zij zelf het beleid uitvoeren. }\end{array}$ \\
\hline Zinloosheid voor de samenleving & $\begin{array}{r}\text { De perceptie van de professionals over de toegevoegde waarde van } \\
\text { het beleid aan belangrijke doelen voor de samenleving. }\end{array}$ \\
\hline Zinloosheid voor de eigen cliënten & $\begin{array}{r}\text { De perceptie van de professionals over de toegevoegde waarde van } \\
\text { het beleid voor hun eigen cliënten. }\end{array}$ \\
\hline
\end{tabular}

Dit artikel maakt om twee redenen gebruik van het raamwerk van beleidsvervreemding. Ten eerste is het raamwerk specifiek ontwikkeld voor publieke professionals die beleid invoeren. Zo analyseert de dimensie zinloosheid voor de samenleving de toegevoegde waarde van het beleid voor maatschappelijk relevante doelen. Dit is bij uitstek geschikt voor analyses binnen een publieke context. Ten tweede is het raamwerk van beleidsvervreemding een van de weinige raamwerken in de bestuurskunde dat gekwantificeerd is op basis van psychometrisch strenge criteria. Dit kan waardevol zijn bij het grootschalig analyseren op basis van kwantitatief onderzoek (zie methode). 


\section{Beleidsvervreemding en weerstand tegen nieuw beleid}

$\mathrm{Na}$ de beknopte bespreking van het model van beleidsvervreemding kunnen de relaties tussen de dimensies van beleidsvervreemding en weerstand tegen nieuw beleid worden gelegd. Weerstand tegen nieuw beleid wordt gedefinieerd als de intentie van de professional om zich niet in te zetten voor de uitvoering van het beleid (zie ook Ajzen, 1991; Metselaar, 1997). Vergelijkbare beschrijvingen zijn te vinden in innovatieliteratuur, waar gesproken wordt over 'weerstand tegen innovatie' (Borins, 2001; Osborne \& Brown, 2011).

De verwachting is dat meer beleidsvervreemding zorgt voor meer weerstand tegen nieuw beleid. Als we bijvoorbeeld kijken naar strategische en tactische machteloosheid, is de verwachting dat, hoe minder professionals invloed ervaren op de beleidsinhoud (zoals vastgelegd in wet- en regelgeving) of op de manier waarop hun organisatie het beleid invoert, hoe meer weerstand ze vertonen. Het gaat hier vaak om indirecte invloed. Professionals hebben namelijk niet vaak zelf invloed, maar via hun professionele verenigingen (strategisch niveau) of via de ondernemingsraad (tactisch niveau). Als professionals het gevoel hebben dat hun vertegenwoordigers genoeg invloed hebben op de totstandkoming van het beleid, dan kan dit juist zorgen voor meer steun (Greenwood et al., 2002).

De verwachting is ook dat meer operationele machteloosheid - of minder ervaren autonomie - negatief van invloed is op steun voor het beleid (Hill \& Hupe, 2009). Autonomie is belang bij professionals, aangezien zij ervan uitgaan dat zij een bepaalde mate van vrijheid te hebben bij het uitvoeren van hun werk (Freidson, 2001).

Hiernaast is de verwachting dat meer ervaren zinloosheid voor de samenleving of voor de cliënt zorgt voor meer weerstand tegen het beleid. In tegenstelling tot de uitgebreide verandermanagementliteratuur over invloed en participatie (bijvoorbeeld Bouma, 2009; Lines, 2004; Oreg et al., 2013), is er veel minder te vinden over de rol van ervaren zinvolheid /zinloosheid. De notie van 'case for change' (reden voor verandering) is wel te relateren aan het concept zinloosheid (Higgs \& Rowland, 2005). Een case for change kan aangeven dat er iets moet veranderen, en dat dit waardevol is voor de organisatie, voor de medewerkers en/of voor de cliënten. Als medewerkers het gevoel hebben dat een verandering goede doelen heeft, zullen zij meer bereid zijn deze verandering te steunen. Bij een onduidelijke case for change kunnen professionals zich afvragen wat de zinvolheid is van een dergelijk beleid. Wat is de toegevoegde waarde van het beleid aan bijvoorbeeld het verbeteren van de veiligheid of het verhogen van de zorgkwaliteit? Hiernaast kan een beleid waarde toevoegen aan de samenleving, maar nadelig zijn voor de eigen cliënten van de professional. Zo kan het verlagen van een arbeidsongeschiktheidsuitkering de samenleving minder geld kosten, 
maar zeer negatieve effecten hebben voor de betreffende cliënt. Op basis van bovenstaande verwacht ik dat alle vijf dimensies van beleidsvervreemding zorgen voor meer weerstand tegen nieuw beleid.

Tot slot verwacht ik dat de impact van dimensies van beleidsvervreemding af kan hangen van de professie waartoe iemand behoort (Freidson, 2001; Scott, 2004). Zoals in de methode hieronder wordt beschreven, analyseer ik de ervaringen van zorgprofessionals (psychiaters, psychologen, psychotherapeuten) met een nieuw beleid. Ik maak een onderscheid tussen de medische professie (psychiaters) en niet-medische professies (psychologen, psychotherapeuten) (Neukrug, 2011; Onyett et al., 1997). Ik analyseer of het behoren tot de medische professie een rol speelt bij de invloed van de dimensies van beleidsvervreemding op weerstand tegen nieuw beleid. Zijn bepaalde dimensies van beleidsvervreemding belangrijker voor medische professionals dan voor niet-medische professionals?

\section{Onderzoeksmethode}

\section{Casusbeschrijving}

Er is een vragenlijst uitgezet onder Nederlandse psychiaters, psychologen en psychotherapeuten die een nieuw beleid moeten invoeren: Diagnose Behandeling Combinaties (DBC's). Het DBC-beleid is in 2008 in de geestelijke gezondheidszorg ingevoerd. Voor de invoering van het DBC-beleid was de praktijk (simpel gesteld) dat hoe meer sessies een professional had met een patiënt, hoe meer vergoedingen hij/zij ontving. Dit werkte volgens sommigen kostenverhogend. Het DBC-beleid veranderde de situatie door een standaard aantal minuten en bijbehorend tarief voor elke aandoening (zoals een milde depressie) te bepalen. Het DBC-beleid behoort tot de Wet Marktordening Gezondheidszorg. De Wet Marktordening Gezondheidszorg en het DBC-beleid kunnen worden gezien als de invoering van gereguleerde competitie in de zorg, in lijn met New Public Management trends.

\section{Steekproeftrekking en respons}

De steekproef bestond uit 5.199 professionals die lid zijn van twee landelijke GGZ verenigingen (Nederlands Instituut voor Psychologen, NIP en de Nederlandse Vereniging voor Psychiaters, NVvP). Via een e-mail en twee herinneringen is een respons van 1.317 professionals (25\%) bereikt. De gemiddelde leeftijd (48 jaar) en de man-vrouw verdeling (66\% vrouw) kwam redelijk overeen met de landelijke gemiddeldes voor GGZ-professionals (44 jaar, 69\% vrouw) (Palm et al., 2008). 


\section{Operationalisatie variabelen}

Vijf-punt Likert antwoordschalen zijn gebruikt voor alle items. De Cronbach alpha van alle schalen was ruim voldoende $(, 83-, 96)$.

\section{Meten van dimensies van beleidsvervreemding}

De schalen van beleidsvervreemding zijn gebaseerd op Tummers (2012). In navolging van de aanbevelingen van DeVellis (2011) zijn er sjablonen gebruikt om de items van de schalen te ontwerpen. Sjablonen geven de onderzoeker de mogelijkheid om algemene termen te vervangen door specifiekere termen die passen bij de context. Op basis van expert interviews en documentanalyse zijn de termen "beleid", "professionals", "organisatie", "cliënten" en "Ministerie" vervangen door respectievelijk "DBC-beleid", "zorgprofessionals", "instelling", "patiënten" en "Ministerie van VWS". Dit maakt het gemakkelijker voor professionals om de stellingen te begrijpen. Ook zijn op basis van de interviews en documentanalyse drie doelen voor het DBC-beleid onderscheiden, nodig voor het meten van de mate van ervaren zinloosheid voor de samenleving:

1. Verhogen van de transparantie in de kosten en kwaliteit

2. Verhogen van de efficiëntie

3. Verhogen van de keuzemogelijkheden voor cliënten

Strategische machteloosheid is gemeten via zes items. Een voorbeelditem is "Professionals hadden volgens mij veel te weinig macht om het beleid te beïnvloeden". Tactische machteloosheid is ook gemeten met 6 items, zoals "In mijn organisatie konden vooral professionals bepalen hoe het beleid werd uitgewerkt" (R). Ook operationale machteloosheid is gemeten met 6 items. Een voorbeelditem op deze schaal is "Bij het werken met het beleid kan ik veel te weinig maatwerk voor mijn cliënten leveren".

Een voorbeelditem voor zinloosheid voor de maatschappij is "lk denk dat het beleid op de lange termijn leidt tot beleidsdoel 2" (hier: verhogen van efficiëntie). Gezien de hoge samenhang tussen de waardering van de verschillende drie doelen zijn deze samengevoegd tot een schaal. Een oorzaak voor deze grote samenhang is dat als zorgprofessionals het gevoel hadden dat het DBC-beleid ineffectief was, zij verwachten dat het DBC-beleid geen van haar doelstellingen behaalde (Tummers, 2010). Ze maken geen onderscheid tussen de effectiviteit voor verschillende doelen. De schaal bestond zodoende uit 12 items. De schaal 
voor zinloosheid voor cliënten bestond uit vijf items. Een voorbeelditem is "Dankzij het beleid kan ik de problemen van mijn cliënten beter oplossen" (R).

Weerstand tegen nieuw beleid is gemeten via de gevalideerde vijf-item schaal van Metselaar (1997). Hier vervangen we 'de verandering' door 'het DBC-beleid'. Een voorbeelditem is “Ik ben van plan om mijn collega's te overtuigen van de voordelen van de DBC-regelgeving".

Hiernaast zijn een aantal controlevariabelen opgenomen, zoals geslacht, leeftijd, beroep (psychiater=medische professie, psychologen en psychotherapeuten=niet medische professie) en leidinggevende positie.

\section{Resultaten}

Om te onderzoeken of de dimensies van beleidsvervreemding de weerstand tegen nieuw beleid verklaren, is een regressieanalyse uitgevoerd. Deze is weergegeven in Tabel 2.

Tabel 2 Regressieanalyse op weerstand tegen nieuw beleid

\begin{tabular}{|c|c|}
\hline & Invloed op weerstand tegen nieuw beleid \\
\hline Geslacht (vrouw) &,$- 06^{\star}$ \\
\hline Leeftijd & 04 \\
\hline Beroep (Psychiater) &, $06^{*}$ \\
\hline Leidinggevende &,$- 08^{\star \star}$ \\
\hline Strategische machteloosheid & ,09** \\
\hline Tactische machteloosheid &, $11^{\star \star}$ \\
\hline Operationele machteloosheid &, $12^{\star \star}$ \\
\hline Zinloosheid voor samenleving & ,28** \\
\hline Zinloosheid voor cliënten & ,23** \\
\hline Interactie Strategische machteloosheid \& Psychiater &, $08^{\star \star}$ \\
\hline Interactie Tactische machteloosheid \& Psychiater & ,03 \\
\hline Interactie Operationele machteloosheid \& Psychiater &,- 01 \\
\hline Interactie Zinloosheid voor samenleving \& Psychiater & ,07* \\
\hline Interactie Zinloosheid voor cliënten \& Psychiater &,- 04 \\
\hline Aangepaste $\mathrm{R}^{2}$ &, $45^{\star \star}$ \\
\hline
\end{tabular}

Een aantal zaken valt op als we kijken naar Tabel 2. Ten eerste blijkt dat de dimensies van beleidsvervreemding - samen met de controlevariabelen - veel variantie van weerstand tegen nieuw beleid verklaren (45\%). Dit komt overeen met de uitkomsten uit het eerdere onderzoek onder 478 zorgprofessionals (41\%) (Tummers, 2011). Alle dimensies zijn significant en positief van invloed op weerstand, zoals ook was verwacht. Dit is in 
tegenstelling tot het eerdere onderzoek, toen strategische en tactische machteloosheid insignificant waren. Ten tweede blijkt dat vooral de zinloosheid dimensies een sterke invloed hebben (.22-.28), terwijl de invloed van de dimensies van machteloosheid een stuk zwakker is (.11-.12). Dit is in lijn met het eerdere onderzoek.

Tot slot blijkt dat de professie invloed heeft op de weerstand tegen nieuw beleid. Psychiaters (behorend tot de medische professie) vertonen meer weerstand tegen nieuw beleid. Ook blijkt dat, als psychiaters het gevoel hebben dat hun professionele vereniging geen invloed heeft op de totstandkoming van het beleid op nationaal niveau (strategische machteloosheid) dan vergroot dit hun weerstand tegen het beleid sterk, sterker dan bij nietpsychiaters. Dit is in lijn met de verwachting van een sterkere beroepsgroep (medische beroepsgroep) om meer betrokken te worden bij beleidsontwikkeling (Greenwood et al., 2002). Hiernaast is het voor psychiaters belangrijker dat zij de waarde van het beleid zien voor de samenleving. Als zij niet het gevoel hebben dat het beleid waarde toevoegt voor de samenleving, dan vertonen zij veel weerstand, meer dan niet-psychiaters. Meer in het algemeen laten deze resultaten zien dat het van belang is om te analyseren welke professie een bepaald beleid moet uitvoeren. De professie waartoe iemand behoort doet er toe. Door een onderscheid te maken tussen professies laat ik zien hoe het model van beleidsvervreemding 'contingent' is. De volgende sectie interpreteert deze uitkomsten verder en geeft aan welke lessen hieruit kunnen worden getrokken.

\section{Conclusies en discussie}

Het doel van dit artikel was om de oorzaken voor weerstand tegen nieuw beleid te bepalen. Het model van beleidsvervreemding werkte goed aangezien de dimensies van beleidsvervreemding - samen met de controlevariabelen - meer dan $40 \%$ van variantie in weerstand tegen nieuw beleid verklaarde. Op basis hiervan kunnen we concluderen dat de interdisciplinaire aanpak gewerkt lijkt te hebben en het model van beleidsvervreemding goed past bij dit soort vraagstukken.

Naast deze algemene conclusie kunnen we een meer inhoudelijke conclusie trekken, namelijk dat de beleidsmakers en managers meer aandacht moeten geven aan het verhogen van de (ervaren) zinvolheid van het beleid. Uit de analyses blijkt namelijk dat als professionals het gevoel hebben dat het beleid zinloos is voor de samenleving of voor de eigen cliënten, zijn zeer waarschijnlijk weerstand gaan vertonen tegen het beleid. De effecten van invloed tijdens beleidsontwikkeling (strategisch niveau) en invloed tijdens beleidsuitvoering door de organisatie (tactisch niveau) zijn juist veel minder belangrijk. Dit is een interessante bevinding. In de literatuur wordt nu vaak aangegeven dat het belangrijk is dat invloed en autonomie erg belangrijk is voor professionals (Evetts, 2002; Freidson, 2001; 
Levay \& Waks, 2009). Over het belang van ervaren zinvolheid in het werk of van het beleid wordt minder geschreven (May et al., 2004; Tummers \& Knies, 2013). Op basis van de bevindingen wil ik de "invloed van invloed" nuanceren en juist meer aandacht vragen aan de ervaren zinvolheid van beleid.

Wel moet ik opmerken dat de impact van verschillende dimensies van beleidsvervreemding kan verschillen tussen professies: voor sommige professies is het betrekken bij beleidsontwikkeling belangrijker dan voor andere professies. Hiernaast is er maar één effect onderzocht: weerstand tegen nieuw beleid. Vervolgonderzoek kan dieper ingaan op de oorzaken en effecten van zinvol werk en zinvol beleid voor professionals. Hiernaast kan vervolgonderzoek naar beleidsvervreemding aandacht besteden het belang van de (aantasting van) 'professionele identiteit', aangezien dit in de literatuur als zeer relevant wordt beschouwd, maar in dit artikel niet is meegenomen (Hekman et al., 2009; Tonkens et al., 2013; Van den Brink et al., 2006).

Het artikel sluit af met enkele praktische tips voor beleidsmakers, managers en professionals. Ik richt me hier op het verlagen van (ervaren) zinloosheid. De (ervaren) zinloosheid van beleid kan op verschillende manieren worden verlaagd. Zo kunnen beleidsmakers eerst pilots van het beleid opzetten, voordat ze het beleid nationaal uitrollen. Op basis van evaluatie van de pilots kunnen kinderziektes en negatieve bijeffecten worden aangepakt. Hiernaast kunnen beleidsmakers en managers werken aan het verlagen van de ervaren zinloosheid. Soms hebben professionals namelijk het gevoel dat beleid zinloos is, terwijl de resultaten redelijk positief zijn. Beleidsmakers kunnen successen van het beleid communiceren naar professionals, of evaluaties laten uitvoeren naar de opbrengsten en kosten van een bepaald beleid, en deze vervolgens communiceren aan verschillende doelgroepen.

Hiernaast kunnen beleidsmakers en managers invloed als middel gebruiken om beleid zinvoller te maken. Zo kunnen zij professionals betrekken om de kwaliteit en haalbaarheid van het beleid te verbeteren. Dit kan zowel op nationaal als op organisatieniveau gebeuren. Invloed is dan geen doel op zich, maar een middel om het beleid te verbeteren.

Naast beleidsmakers en managers kunnen professionals zelf ook de zinvolheid van beleid vergroten. Ook zij zijn verantwoordelijk zijn voor de totstandkoming van goed beleid. Professionals kunnen zitting nemen in klankbordgroepen van hun eigen professionele vereniging, meewerken binnen hun eigen organisatie aan de implementatie van beleid, posities als 'managing professionals' op zich nemen of opinieartikelen schrijven met mogelijke oplossingsrichtingen. Via verschillende wegen kan zo de (ervaren en daadwerkelijke) zinloosheid van beleid voor de samenleving en voor cliënten worden 
verlaagd. Uiteindelijk kan dit zinvol zijn voor zowel beleidsmakers, managers en professionals. 


\section{References}

Ackroyd, S. (1996). Organization contra organizations: Professions and organizational change in the United Kingdom. Organization Studies, 17(4), 599-621.

Ajzen, I. (1991). The theory of planned behavior. Organizational Behavior and Human Decision Processes, 50(2), 179-211.

Berkovich, I. (2011). No we won't! Teachers' resistance to educational reform. Journal of Educational Administration, 49(5), 563-578.

Borins, S. (2001). The challenge of innovating in government. Washington, DC: IBM Center for the Business of Government.

Bouma, J. T. (2009). Why participation works: The role of employee involvement in the implementation of the customer relationship management type of organizational change. Groningen: SOM Research School.

Brandsen, T., \& Honingh, M. (2013). Professionals and shifts in governance. International Journal of Public Administration, 36(12), 876-883.

Brehm, J., \& Gates, S. (1999). Working, shirking, and sabotage: Bureaucratic response to a democratic public. Michigan: University of Michigan Press.

Carnall, C. A. (2007). Managing change in organizations. Essex: Pearson Education.

De Bruijn, J. A. (2010). Managing professionals. London: Routledge.

DeHart-Davis, L., \& Pandey, S. K. (2005). Red tape and public employees: Does perceived rule dysfunction alienate managers? Journal of Public Administration Research and Theory, 15(1), 133-148.

DeVellis, R. F. (2011). Scale development: Theory and applications (2nd ed.). Thousand Oaks: Sage.

Duyvendak, W. G. J., Knijn, T., \& Kremer, M. (Eds.). (2006). Policy, people, and the new professional. de-professionalisation and re-professionalisation in care and welfare. Amsterdam: Amsterdam University Press.

Evetts, J. (2002). New directions in state and international professional occupations: Discretionary decision-making and acquired regulation. Work, Employment \& Society, 16(2), 341-353.

Ewalt, J. A. G., \& Jennings, E. T. (2004). Administration, governance, and policy tools in welfare policy implementation. Public Administration Review, 64(4), 449-462.

Ford, J. D., Ford, L. W., \& D'Amelio, A. (2008). Resistance to change: The rest of the story. Academy of Management Review, 33(2), 362-377.

Freidson, E. (2001). Professionalism: The third logic. Cambridge: Cambridge University Press.

Gleeson, D., \& Knights, D. (2006). Challenging dualism: Public professionalism in 'troubled'times. Sociology, 40(2), 277-295. 
Greenwood, R., Suddaby, R., \& Hinings, C. R. (2002). Theorizing change: The role of professional associations in the transformation of institutionalized fields. The Academy of Management Journal, 45(1), 58-80.

Hekman, D. R., Bigley, G. A., Steensma, H. K., \& Hereford, J. F. (2009). Combined effects of organizational and professional identification on the reciprocity dynamic for professional employees. The Academy of Management Journal, 52(3), 506-526.

Higgs, M., \& Rowland, D. (2005). All changes great and small: Exploring approaches to change and its leadership. Journal of Change Management, 5(2), 121-151.

Hill, M., \& Hupe, P. (2009). Implementing public policy (2nd ed.). Thousand Oaks: Sage.

Kanungo, R. N. (1982). Work alienation: An integrative approach. New York: Praeger Publishers.

Kickert, W. J. M. (2010). Managing emergent and complex change: The case of dutch agencification. International Review of Administrative Sciences, 76(3), 489-515.

Klopper-Kes, H. A. H. J., Siesling, S., Meerdink, N., Wilderom, C. P. M., \& Van Harten, W. H. (2010). Quantifying culture gaps between physicians and managers in dutch hospitals: A survey. BMC Health Services Research, 10(1), 86.

Kuipers, B. S., Higgs, M. J., Kickert, W. J. M., Tummers, L. G., Grandia, J., \& Van der Voet, J. (2014). The management of change in public organisations: A literature review. Public Administration, Early view. DOI: 10.1111/padm.12040

Levay, C., \& Waks, C. (2009). Professions and the pursuit of transparency in healthcare: Two cases of soft autonomy. Organization Studies, 30(5), 509-527.

Lines, R. (2004). Influence of participation in strategic change: Resistance, organizational commitment and change goal achievement. Journal of Change Management, 4(3), 193215.

Marx, K. (1961 [1844]). Alienated labor. In K. Marx (Ed.), Economic and philosophic manuscripts of 1844 (pp. 67-83). Moscow: Foreign Languages Publishing House.

May, D. R., Gilson, R. L., \& Harter, L. M. (2004). The psychological conditions of meaningfulness, safety and availability and the engagement of the human spirit at work. Journal of Occupational and Organizational Psychology, 77(1), 11-37.

Metselaar, E. E. (1997). Assessing the willingness to change: Construction and validation of the DINAMO. (Doctoral dissertation, Free University of Amsterdam).

Neukrug, E. (2011). The world of the counselor: An introduction to the counseling profession Thomson Brooks/Cole.

Noordegraaf, M. (2011). Risky business: How professionals and professional fields (must) deal with organizational issues. Organization Studies, 32(10), 1349-1371.

Noordegraaf, M., \& Steijn, A. J. (Eds.). (2013). Professionals under pressure: Perspectives on professionals and professionalism. Amsterdam: Amsterdam University Press. 
Noordegraaf, M. (2014). Reconfiguring professional work: Changing forms of professionalism in public services. Administration \& Society, Early View. DOI: 0095399713509242.

Nutting, P. A., Crabtree, B. F., Miller, W. L., Stange, K. C., Stewart, E., \& Jaén, C. (2011). Transforming physician practices to patient-centered medical homes: Lessons from the national demonstration project. Health Affairs, 30(3), 439-445.

Onyett, S., Pillinger, T., \& Muijen, m. (1997). Job satisfaction and burnout among members of community mental health teams. Journal of Mental Health, 6(1), 55-66.

Oreg, S., Michel, A., \& By, R. T. (2013). The psychology of organizational change: Viewing change from the employee's perspective Cambridge University Press.

Osborne, S. P., \& Brown, L. (2011). Innovation, public policy and public services delivery in the UK. the word that would be king? Public Administration, 89(4), 1335-1350.

Palm, I., Leffers, F., Emons, T., Van Egmond, V., \& Zeegers, S. (2008). De GGz ontwricht: Een praktijkonderzoek naar de gevolgen van het nieuwe zorgstelsel in de geestelijke gezondheidszorg. Den Haag: SP.

Powell, W. W., \& Colyvas, J. A. (2008). Microfoundations of institutional theory. In R. Greenwood, C. Oliver, K. Sahlin \& R. Suddaby (Eds.), The SAGE handbook of organizational institutionalism (pp. 276-298). London: Sage.

Raelin, J. A. (1986). The clash of cultures: Managers and professionals. Boston: Harvard Business Press.

Scott, W. R. (1994). Institutions and organizations: Toward a theoretical synthesis. Thousand Oaks, CA: Sage.

Scott, W. R. (2004). Institutional theory: Contributing to a theoretical research program. In K. Smith, \& M. Hitt (Eds.), Great minds in management: The process of theory development (pp. 460-484). Oxford University Press: Oxford.

Seeman, M. (1959). On the meaning of alienation. American Sociological Review, 24(6), 783-791.

Tonkens, E., Bröer, C., Van Sambeek, N., \& Van Hassel, D. (2013). Pretenders and performers: Professional responses to the commodification of health care. Social Theory \& Health, , 1-20.

Tummers, L. G. (2010). De bereidheid van GGZ-zorgprofessionals om te werken met DBC's. Rotterdam: Erasmus Universiteit Rotterdam.

Tummers, L. G. (2011). Explaining the willingness of public professionals to implement new policies: A policy alienation framework. International Review of Administrative Sciences, $77(3), 555-581$.

Tummers, L. G. (2012). Policy alienation of public professionals: The construct and its measurement. Public Administration Review, 72(4), 516-525. 
Tummers, L. G., Bekkers, V. J. J. M., \& Steijn, A. J. (2009). Policy alienation of public professionals: Application in a New Public Management context. Public Management Review, 11(5), 685-706.

Tummers, L. G., \& Knies, E. (2013). Leadership and meaningful work in the public sector. Public Administration Review, 73(6), 859-868.

Van den Brink, G., Jansen, T., \& Pessers, D. (2006). Beroepszeer: Waarom Nederland niet goed werkt. Amsterdam: Boom. 